\title{
The effect of occipital ablation on visual sensitivity in young and old rats
}

\author{
VIRGINIA L. GOETSCH and WALTER ISAAC \\ University of Georgia, Athens, Georgia
}

\begin{abstract}
The effect of occipital ablation on the visual sensitivity to low levels of illumination in young and old rats was studied using a signal detection task. A significant decrease in sensitivity following ablation was found for both age groups, which could be eliminated by increasing the apparent brightness of the visual stimuli. Results are discussed in terms of the role of the occipital cortex in detecting low levels of illumination.
\end{abstract}

Research concerning the effects of occipital ablation on absolute visual threshold has produced a wide range of results. Marquis (1934) found that occipital ablation produced no effect on absolute visual threshold in dogs. Brigman and Smith (1942) found a five hundredfold increase in absolute visual threshold in cats following total occipital ablation and a fivefold increase in threshold following partial occipital ablation. Further, the findings of Bridgmen and Smith (1942) demonstrate that the deficits seen are not a consequence of cortical insult, but are the consequence of total ablation of the visual projection cortex. Recently, Kenshalo (1976) found an increase in the absolute visual threshold of rats following bilateral occipital ablation.

After finding that the performance of occipitally ablated rats on a light-dark discrimination task was inferior at intensities well above visual threshold as well as at lower intensities, Cooper, Freeman, and Pinel (1967) suggested that performance deficits were due to postoperative changes in the sensory criterion (the sensory level set by the subject for deciding whether a visual signal was administered or not) rather than to a deficit in visual sensitivity. Lashley (1935) also suggested that deficits on a light-dark discrimination task following occipital ablation were due to a decrease in the subjects' attention. In support of this suggestion, Krechevsky (1936) found that the performance of rats following occipital ablation approached the performance of normal animals when using shock, thereby increasing the attention of the subjects. However, Kenshalo (1976) found no difference in false-alarm rates between occipitally ablated rats and sham-operated animals on a signal detection task using low levels of illumination. Changes in sensory criterion can be observed as changes in false positive or false negative responses, and therefore may reflect changes in motivation or attentional levels (Shiffman, 1976). Thus, Kenshalo's findings

The authors' mailing address is: Department of Psychology, University of Georgia, Athens, Georgia 30602. argue against a performance deficit that is due to changes in sensory criterion after occipital ablation.

The present study was designed to examine the effect of occipital ablation on the ability of young and old rats to detect low levels of illumination and to determine whether deficits in detection of visual stimuli, if found, could be eliminated by increasing the apparent brightness of the stimuli. Prior to ablation, due to deterioration of the retina and yellowing of the lens which occur with age (McFarland, Domey, Warren, \& Ward, 1960; Said \& Weale, 1959), a deficit is expected in the absolute threshold of the old group, as compared with that of the young group. Whether this difference would be the same following occipital ablation was unclear. The improvement in the performance of old rats on a light-conditioned response following occipital ablation, as found by Isaac and Baker (1963), suggests a possible change in the function of the occipital cortex with aging and a change in absolute visual threshold following ablation in older rats that may be different from that seen in younger rats.

\section{METHOD}

\section{Subjects}

The subjects were 20 male hooded rats, 10 aged 60 days and 10 aged 400 days at the beginning of the study. They were housed individually in a colony room that was maintained on a 12-h-light, 12-h-dark schedule. Food was provided ad lib, and water was provided for $\mathbf{3 0} \mathrm{min}$ following each daily experimental session.

\begin{abstract}
Apparatus
The test apparatuses were two black metal boxes measuring $30.0 \mathrm{~cm}$ long, $14.0 \mathrm{~cm}$ wide, and $17.5 \mathrm{~cm}$ high. The boxes rested on a $80.0 \times 50.0 \mathrm{~cm}$ wooden table in the experimental room. The Plexiglas tops of the boxes were hinged, giving access to the interior. The bottoms of the boxes were covered with $1.0 \mathrm{~cm}$ of granulated clay (Cat Comfort absorbant litter). At one end of each box was a $10.0 \times 2.0 \mathrm{~cm}$ removable plastic bar (David Instrument Company). At the opposite end of the boxes, two round holes, $3.25 \mathrm{~cm}$ in diameter and $4.9 \mathrm{~cm}$ apart, were centered $2.5 \mathrm{~cm}$ above the floor. Both of these openings gave access to a transparent Plexiglas panel, which was hinged at the top and which, when pressed, closed an optical switch. An aluminum reinforcer pedestal, $2.0 \mathrm{~cm}$ in front of the wall and extending $3.0 \mathrm{~cm}$ above
\end{abstract}


the floor, was centered between the two circular openings. A solenoid valve was set to deliver $0.15 \mathrm{ml}$ of sugar water through the reinforcer pedestals.

Light stimuli were presented by a bank of green light-emitting diodes located $4.0 \mathrm{~cm}$ behind the left Plexiglas panels; a frostedglass diffusion lens was located between the light source and the panels. The bank of 25 green (540 nm) light-emitting diodes (FLV 340), which produced a luminance of $1.0 \mathrm{fL}$ with steady application of current, was energized 77.8 times per second; the duration of the flashes was controlled by a solid state programming system. The apparent brightness of the light stimulus was varied by controlling the flash durations. This method of varying the visual stimulus has been described in greater detail elsewhere (Lorig, Golden, \& Isaac, 1980). In the present study, the on-times of the flashes were $4,6,8,10,14$, and $32 \mu \mathrm{sec}$, except that, for the final 12 days, the flash durations were changed to $8,12,16$, 20,28 , and $64 \mu \mathrm{sec}$ by the inclusion of a $500-\Omega$ resistor in the brightness-control circuit for the occipitally ablated subjects only. This resistor produced a linear increase in apparent brightness across all six intensities. The levels of illumination produced were not visible to the human observer and, therefore, were not directly measurable.

Data were collected in the two rectangular metal boxes, which were equipped with a level at one end and two response panels at the other end. Solid state programming equipment located in an adjacent room controlled the sequence of events and recorded the data obtained.

\section{Procedure}

During preliminary training, the subjects were trained to set up each trial by pressing the bar at one end of the box and to then press the left panel at the other end of the box if it was illuminated or the right panel if the left panel remained dark. Following preliminary training, the equipment was programmed to allow for the occurrence of 60 trials, with 30 trials in which no light stimulus appeared behind the left panel and 30 trials in which five trials at each of the six flash durations were presented. The order of the stimulus conditions was randomized.

Prior to each daily session, each subject was placed in the experimental room for $\mathbf{3 0}$ min to provide an opportunity for dark adaptation. After the performance of all subjects had stabilized, as determined by analysis of variance, data were taken for 12 days. Following these 12 days, bilateral occipital ablations were performed on half of the young group and half of the old group. The remaining animals served as sham-operated controls. All subjects were allowed 20 days' recovery in the colony room. They were then retrained until their performance had again stabilized, and data were taken for an additional 12 days. Following those 12 days, a 500-8 resistor was included in the brightness control circuit to increase the apparent brightness of all levels by an equivalent increment for the occipitally ablated subjects, and data were then taken for an additional 12 days. At the same time, an additional 12 days' data were obtained from the sham-operated subjects at the six original intensities. During this final 12-day period, the performance of the occipitally ablated subjects at the higher apparent brightness intensities was compared with that of the sham operates at the original intensities.

\section{Surgery Procedure}

All subjects were anesthetized with $50.0 \mathrm{mg} / \mathrm{kg} \mathrm{Nembutal}$ and received $1.50 \mathrm{mg}$ atropine intraparitoneally, along with 15,000 units $(0.05 \mathrm{cc})$ of penicillin injected intramuscularly. The occipital cortex was removed from the experimental subjects by aspiration; sham operates underwent the same procedure, including opening of the skull, but without removal of the cortex.

\section{RESULTS}

The preoperative data (Figure 1) from the young and old subjects were analyzed using analysis of vari-

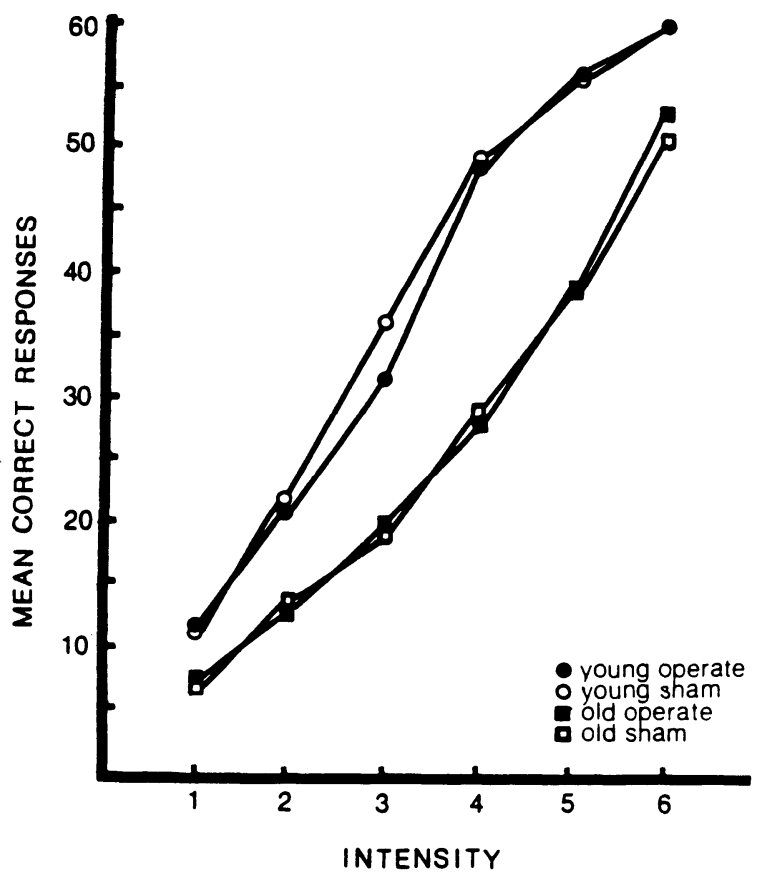

Figure 1. Mean correct responses (detections) of young and old operates and sham operates across intensities prior to surgery.

ance in a 2 (age) $\times 2$ (sham/operate) $\times 6$ (intensity) $\times 2$ (6-day blocks) mixed design with two repeated measures (intensity and blocks) and two independent measures (age and sham/operate). As expected (Goetsch \& Isaac, 1982), a significant improvement in the number of detections with increasing brightness was found $[F(5,176)=356.857, p<.001]$. A significant age difference in the number of detections was also found $[F(1,16)=85.648, p<.001]$, with the young animals showing superior performance. The interaction between age and light intensity was also found to be significant $[F(5,176)=11.233$, $p<$ $.001]$. The difference between blocks of trials did not approach significance, nor did any of its interactions, indicating stability of performance for both groups. No differences were found between the subjects that would later comprise the sham and operate groups, and none of the interactions approached significance. These findings indicate that, prior to surgery, the sham and operate groups were equivalent in their ability to detect light.

Postoperative data (Figure 2) were analyzed using analysis of variance in the same mixed design as was used to analyze the preoperative data. Again, a significant difference was found in the number of detections across the six light intensities $[F(5,176)=509.606$, $\mathrm{p}<.001]$ and between the young and old subjects $[F(1,16)=38.639, p<.001]$. The effects of age and light intensity were again not independent, and their interaction was found to be significant $[F(5,176)=$ $27.838, p<.001$ ]. In addition, a significant difference was found between the sham and operate groups 


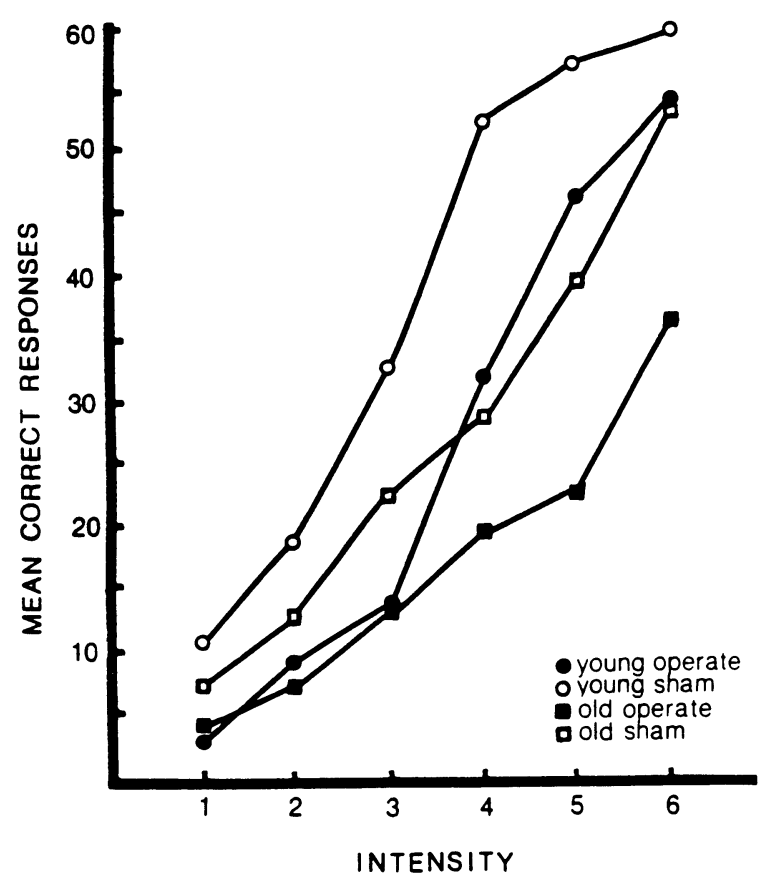

Figure 2. Mean correct responses (detections) of young and old operates and sham operates across intensities following surgery, prior to the resistor change.

$[F(1,16)=45.898, p<.001]$, showing that ablation of the occipital cortex produced a decrement in the subjects' ability to detect light. The interaction between the sham/operate groups and intensity was also found to be significant $[F(5,176)=8.302$, $p<$ .001 ], as was the interaction between age, light intensity, and surgical treatment $[F(5,176)=7.759$, $\mathrm{p}<.001]$. No significant differences were found across blocks of days or among any of the other interactions.

Analysis of the data obtained following the resistor change for the operate group (Figure 3) was done using analysis of variance, again with the same mixed design as was employed for the two previous analyses. A significant age difference in detection of light was again found $[F(1,16)=37.542, p<.001]$, along with a significant increase in detections across light intensities $[F(5,176)=991.500, p<.001]$. The interaction between age and light intensity was also found to be significant $[F(5,176)=14.397, p<.001]$. All other factors (sham/operate and blocks) and their interactions did not approach significance, indicating that the effects of the surgery had been removed by the increase in brightness produced by the resistor change. The fact that the same resistor change compensated for the decrease in detection of light in the operates of both age groups indicates that occipital ablation produced an equivalent decrement in detection of light in both young and old subjects.
Analysis of false-alarm data (false positive responses) was performed using analysis of variance in a 2 (age) $\times 2$ (sham/operate) $\times 2$ (pre- and postsurgery) mixed design with one repeated measure (pre- and postsurgery) and two independent measures (age and sham/operate). No significant main effects for any of the factors were found, and none of the interactions approached significance. These findings indicate that the criterion on which the subjects were basing their responses were the same across groups and remained constant throughout the study.

\section{Histological Findings}

After testing, all subjects were given an overdose of Nembutal and were immediately perfused with physiological saline followed by $10 \%$ Formalin. The brains were frozen and sectioned at $\mathbf{4 0}$ microns. Every 10th section was mounted and stained with cresyl violet.

Visual examination of the ablations indicated that the visual cortex had been completely removed or undercut. The extent of the largest and smallest occipital ablations are shown in Figure 4. Examination of the stained sections revealed degeneration of the dorsal portion of the lateral geniculate nucleus of the thalamus, as would result from occipital ablation.

Visual examination of a sample of the sham ablations revealed no damage to the occipital cortex.

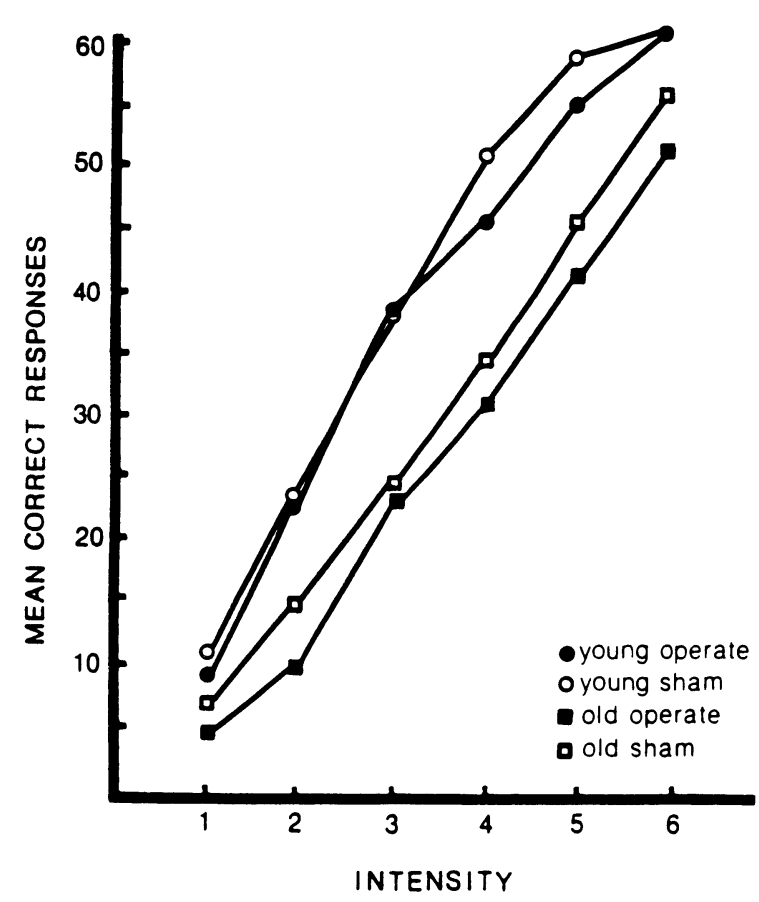

Figure 3: Mean correct responses (detections) of the young and old sham groups at the six original intensities compared with the detections made by the young and old operate groups at the six brighter intensities produced by the resistor change. 


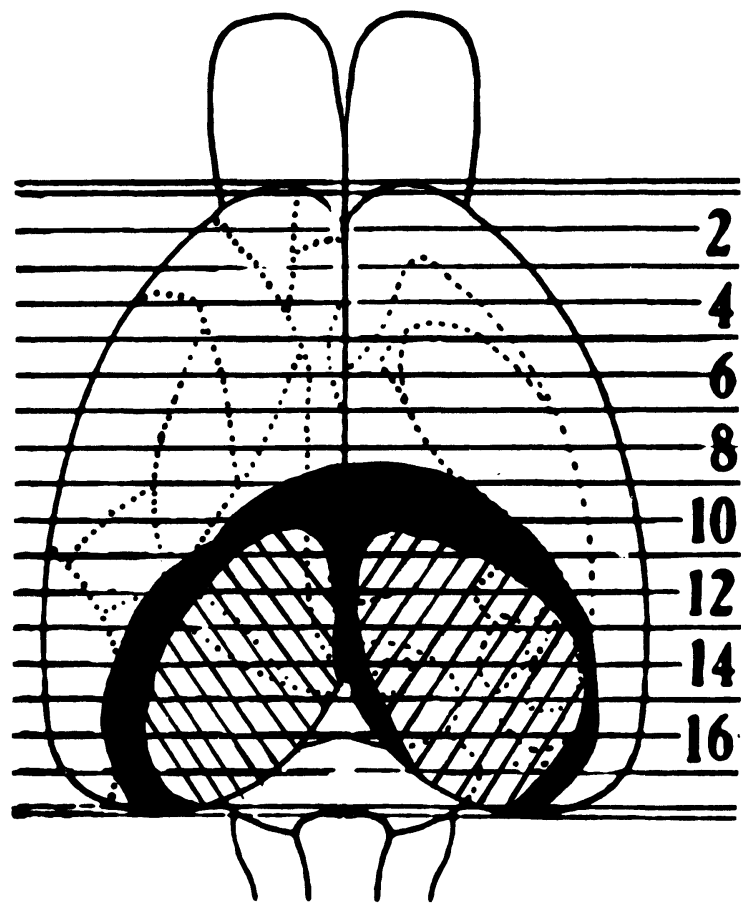

Figure 4. Extent of the largest and smallest occipital ablations.

\section{DISCUSSION}

As expected, the subjects' detection of light improved significantly with increasing light intensity both before and after surgery. The young subjects showed superior performance when compared with that of the old subjects, also both before and after surgery. The presurgery age difference found is consistent with the findings of Goetsch and Isaac (1982), who reported differences in detection of near-threshold levels of illumination by young and old rats. Birren (1959) also found significant age declines in sensory processes, including visual sensitivity, in the human. These differences may be explained at least partially as the result of age-related changes in the peripheral visual apparatus such as deterioration of the retina (McFarland et al., 1960) and yellowing of the lens (Said \& Weale, 1959).

Changes in the central nervous system, specifically in the visual cortex, may also play a role in producing the observed decrement in performance found in the old subjects prior to ablation. In general, there are many structural changes in the cerebral cortex which occur with age. In the human some atrophy of the nervous tissue occurs with narrowing of the cerebral gyri and widening and deepening of the sulci between them, accompanied by a loss of weight of the brain as a whole (Andrew, 1971). Brody (1955) found that there was an age-related deterioration of the cerebral cortex that was most pronounced in the frontal, occipital, and superior temporal lobes.
The effect of occipital ablation was to decrease visual sensitivity in both young and old rats. Both ablation groups continued to show improved detection of light with increasing intensity, although their performance was significantly poorer than that of the same-age sham-ablation group. It is interesting to note that the postoperative difference in performance of the two operate groups is not apparent at the lower intensities used (Figure 2). At these intensities, performance is at a level below chance $(50 \%)$.

Although, since training involved a nonstandardized procedure, no data were collected on the amount of time required for acquisition or retraining of the signal detection task, it was noted that the old subjects required more pre- and postoperative training than the young subjects. However, no obvious differences were noted between the same-aged sham and ablation groups following surgery.

The data obtained following the resistor change also indicate that occipital ablation produces a decrement in performance which can be eliminated by increasing the intensity of the visual stimuli. These findings indicate that occipital ablation produces a shift in absolute visual threshold.

A reasonable explanation of these findings is that the performance deficit found with both young and old rats following occipital ablation is directly attributable to a sensory deficit. Furthermore, the fact that no differences were found in false-alarm rates across any of the groups either before or after surgery indicates that differences in performance were due to differences in the ablated subjects' ability to detect light rather than any differences in attention or motivation.

\section{REFERENCES}

ANDREw, W. The anatomy of aging in man and animals. New York: Grune and Stratton, 1971.

Birren, J. E. Handbook of aging and the individual: Psychological and biological aspects. Chicago: University of Chicago Press, 1959.

Bridgman, C. S., \& Smith, K. U. The absolute threshold of vision in cat and man with observations on its relation to the optic cortex. American Journal of Physiology, 1942, 136, 463-466.

Brody, H. Organization of the cerebral cortex. III. A study of aging in the human cerebral cortex. Journal of Comparative Neurology, 1955, 102, 511-556.

Cooper, R. M., Freeman, I., \& Pinel, J. P. J. Absolute threshold of vision in the rat after removal of striate cortex. Journal of Comparative and Physiological Psychology, 1967, 64, 34-39.

Goetsch, V. L., \& IsaAc, W. Age and visual sensitivity in the rat. Physiological Psychology, 1982, 10, 199-201.

ISAAC, W., \& BAKER, E. J. A changing effect of cortical ablation with age. Journal of Comparative and Physiological Psychology, 1963, 56, 167-168.

KenshaLo, D. R. Influences of occipital and superior colliculus lesions, singly and in combination, on the rat's absolute visual threshold. Unpublished doctoral dissertation, University of Georgia, 1976.

KRECHEVSKY, I. Brain mechanisms and brightness discrimination 
learning. Journal of Comparative Psychology, 1936, 21, 405-415.

LASHLEY, K. S. The mechanism of vision: VII. Nervous structures concerned in the acquisition and retention of habits based on reactions to light. Comparative Psychology Monograph, 1935, 2, 43-79.

Lorig, T. S., Golden, A. J., \& IsaAc, W. A programmable circuit for varying light intensity. Behavior Research Methods \& Instrumentation, 1980, 12, 639.

MARQuis, D. Effects of removal of the visual cortex in mammals with observations on the retention of light discrimination by dogs: Localization of function in the cerebral cortex. Research Publications of the Association of Nervous and Mental Disease, 1934, 13, 558-592.
McFarland, R. A., Domey, R. G., Warren, A. B., \& Ward, D. C. Dark adaptation as a function of age: I. A statistical analysis. Journal of Gerontology, 1960, 15, 149-154.

Said, F. S., \& Weale, R. A. The variation with age of the spectral transmissivity of the living human crystalline lens. Gerontologia, 1959, 3, 213-231.

Shiffman, H. R. Psychophysics. Sensation and perception: An integrated approach. New York: Wiley, 1976.

(Manuscript received June 3, 1983;

revision accepted for publication August 22, 1983.) 